\title{
FALÊNCIA SOBERANA: UMA HERESIA DESDE DENTRO $^{1}$
}

\section{André Moreira Cunha}

\section{INTRODUÇ̃̃O}

Nos últimos anos, o desenvolvimento das finanças internacionais foi marcado por duas importantes inflexões. Até meados de 1997, o otimismo quanto ao avanço da globalização financeira estava fundado em um processo contínuo de mudança nas condições institucionais, no sentido de uma crescente liberalização e desregulamentação. Condições permissivas no lado da oferta - novas tecnologias de informação, crescente liquidez e juros em queda nos países industrializados, inovações financeiras, etc. - e no lado da demanda - desregulamentação e novas oportunidades de investimento, especialmente aquelas associadas às privatizações - garantiram a absorção de volumes crescentes de capitais pelos países em desenvolvimento.

Porém, a partir da crise asiática, em 1997 e 1998, e de uma posterior seqüência de crises financeiras, aquele sinal inverteu-se: verificou-se uma queda contínua na entrada líquida de capitais nas economias emergentes e um aumento no questionamento sobre as virtudes da globalização, em especial no que se refere à liberalização financeira.

Os governos do $\mathrm{G} 7^{3} \mathrm{e}$ os principais órgãos multilaterais passaram a liderar um esforço de reestruturação da arquitetura financeira internacional (AFI, de agora em diante). Tem sido enfatizada a necessidade dos países em desenvolvimento fortalecerem suas instituições domésticas, de modo a tornar mais transparentes as informações sobre a qualidade de suas empresas

1 Trabalho apresentado no VII Encontro de Economia Política, Curitiba, maio de 2002. Original: março de 2002. Versão atualizada em dezembro de 2002. Todas as citações em idioma estrangeiro foram traduzidas pelo autor.

${ }^{2}$ Economista (UFRGS), Mestre em Economia (Unicamp, 2001-2003). Professor Adjunto e Pesquisador da Unisinos (função atual).

${ }^{3}$ EUA, Alemanha, Japão, Canadá, França, Inglaterra e Itália. 
industriais, instituições financeiras e governos. Além disso, tem-se discutido a reformulação na atuação das instituições de Bretton Woods.

Neste contexto, agendas políticas que estavam marginalizadas no debate acadêmico e político do establishment passaram ao front das discussões sobre o fortalecimento da AFI. Em especial, dois temas merecem destaque: a criação de condições para que os países em crise não sofram "corridas de credores" nos moldes da legislação norte-americana de falências, ao que se pode denominar de "falência soberana"; associada à possibilidade da imposição de limites - temporários ou não - à plena conversibilidade da conta capital. O presente artigo tem por objetivo explorar algumas das implicações do primeiro tema, a "falência soberana".

A proposta de criação de um mecanismo institucional capaz de dar suporte a processos ordenados de reestruturação de dívidas soberanas parece sinalizar para a insuficiência das reformas na AFI até então defendidas pelo Fundo Monetário Internacional (FMI ou IMF). Na medida em que sugere a institucionalização da resolução de conflitos entre credores e devedores, este tipo de proposta vai de encontro às medidas de livre negociação normalmente defendidas pelos agentes privados que operam nos mercados financeiros e seus representantes institucionais. O tema da "falência soberana" contrasta com a agenda prévia de disseminação global de políticas do tipo hands off. Por conta disso, não deixa de parecer irônico o FMI liderar este tipo de discussão. É quase que uma heresia desde dentro do establishment oficial.

Além desta introdução, este artigo possui mais três seções. A seguir, são destacados alguns fatos estilizados do ciclo recente de boomand-bust das finanças internacionais, com ênfase nos impactos da crescente instabilidade na formatação da reforma da AFI. Na seqüência, exploram-se as implicações da possibilidade de países decretarem "falência soberana", objeto central deste artigo. Em seguida, são feitas algumas considerações finais. 


\section{CRISES FINANCEIRAS ${ }^{4}$ E REFORMAS NA ARQUITETURA FINANCEIRA INTERNACIONAL}

As décadas que se seguiram à ruptura do sistema de câmbio fixo derivado do acordo de Bretton Woods foram marcadas pela ocorrência sistemática de episódios de crise financeira. O FMI (IMF, 1998) identificou, para o período 1975-1997, 158 episódios de crises cambiais e 54 de crises bancárias. ${ }^{5}$ Tais crises foram mais freqüentes nos países em desenvolvimento e implicaram custos significativos tanto para viabilizar a reestruturação dos sistemas financeiros, quanto em termos de queda do produto. Nos casos mais graves, os custos fiscais das crises oscilaram entre $30 \%$ e $40 \%$ do PIB. A perda de renda, calculada pela diferença entre a linha de tendência do produto e seu resultado após a crise, foi em média de 4,25\% (sendo maior nos países em desenvolvimento).

Algumas regularidades empíricas vêm marcando as crises financeiras recentes: a expansão do crédito doméstico associada à liberalização financeira (interna e externa); alimentando um boom nos mercados reais e financeiros; apreciação da taxa de câmbio; fragilização externa, com a deterioração dos saldos em conta corrente e redução na liquidez (ampliação da

${ }^{4}$ Considera-se crise financeira em um sentido amplo, a que inclui crises cambiais, crises bancárias e crises de balanço de pagamentos (IMF, 1998, AZIZ et.al., 2000, MISHKIN, 2001). As crises cambiais ocorrem quando há um ataque especulativo contra a paridade de uma moeda doméstica, que force sua desvalorização ou gere intervenções governamentais pesadas (vendas de reservas e/ou aumento substancial da taxa de juros para defesa da paridade). As crises bancárias estão associadas à suspensão da conversibilidade dos passivos bancários que se segue às "corridas bancárias" efetivas e/ou potenciais, levando à necessidade de intervenções estatais para provisão de liquidez. E as crises de balanço de pagamentos originam-se da incapacidade de um país honrar o serviço de sua dívida externa, quer ela seja privada, quer seja soberana. Têm-se denominado de crises gêmeas os episódios onde crises cambiais e bancárias ocorrem de forma simultânea, detonando mecanismos perversos de retro-alimentação (KAMINSKY; REINHART, 1995).

${ }^{5}$ Utilizou-se uma amostra com 22 países industrializados e 31 países em desenvolvimento. EUA e Alemanha foram excluídos da amostra que verificou a natureza das crises cambiais, na medida em que suas moedas servem de referência para os demais países, mas foram mantidos nos estudos sobre crises bancárias. (IMF, 1998, nota 85). As crises cambiais foram identificadas pela construção de um índice de pressões nos mercados cambiais, que leva em conta as mudanças nas taxas de câmbio e as perdas de reserva e/ou aumento dos juros para amortizar os ataques especulativos; e as crises bancárias por eventos ex-post como fechamento, estatização e/ou fusões forçadas de instituições, corridas bancárias ou elevados pacotes de auxílio de liquidez pelo governo. 
relação entre passivos e ativos externos e encurtamento das posições passivas); dentre outros fatores. ${ }^{6}$

No plano teórico, os modelos de crise financeira tendem a se dividir em dois grandes grupos: de um lado, há os que buscam as origens das crises na fragilização dos fundamentos econômicos e das instituições domésticas, especialmente no que se refere à regulação dos sistemas financeiros; de outro, os que enfatizam a existência de comportamentos irracionais por parte dos especuladores (manias especulativas, comportamentos de manada, miopia dos agentes, efeito-contágio, etc.), fato agravado em um ambiente de crescente liquidez e escassa regulação. ${ }^{7}$

O debate acadêmico tem influenciado a conformação das políticas de ajuste macroeconômico propostas pelos órgãos multilaterais, com o apoio dos governos do G7. Assim, a visão convencional de que as crises cambiais do final dos anos 1970 e início dos anos 1980 eram o resultado da inconsistência fiscal decorrente de políticas domésticas expansionistas, gerou uma agenda política pautada pela ênfase na adoção do bom comportamento fiscal e monetário. As crises dos anos 1990, suscitaram a criação de novos modelos teóricos, que passaram a enfatizar os efeitos intertemporais de políticas "potencialmente inconsistentes" e das falhas institucionais como a existência de garantias implícitas sobre os empréstimos bancários ou o too big to failure (CUNHA, 2001).

A crise asiática (1997-1998) inaugurou uma fase de retração nos fluxos privados de capitais para os países em desenvolvimento. A ela seguiu-se a crise russa e a falência de um importante fundo hedge norte-ame-

${ }^{6}$ Há uma fértil literatura que busca identificar a natureza das crises financeiras, bem como indicadores que as antecipem. Para uma survey atualizada, ver Kaminsky, Lizondo e Reinhart (1998). Demirgüç-kunt e Detragiache (1998) estudaram 53 países para o período 1980-1995, constatando que a liberalização financeira amplia a possibilidade de ocorrência de crises bancárias, especialmente quando os mecanismos de supervisão do sistema são falhos. Aziz et. al. (2000), do staff do FMI, trabalharam com uma amostra de 50 países para o período 1975-1997. Ainda que considerem não existirem duas crises idênticas, apontam algumas regularidades: "Tipicamente, antes de uma crise cambial a economia estava aquecida: a inflação era relativamente alta e a moeda doméstica estava sobrevalorizada, afetando o setor exportador e o balanço em conta corrente. A política monetária era significativamente expansionista, com o crédito doméstico crescendo fortemente, comprometendo as metas cambiais para países com sistemas de câmbio fixo ou inflexível. Mais ainda, alguns mecanismos de disparo, como o aumento da taxa de juros mundial e o declínio nos termos de intercâmbio, usualmente ampliaram a vulnerabilidade das economias às crises." (p. 24)

${ }^{7}$ Uma revisão desta literatura pode ser encontrada em Cunha (2001) e Cunha e Prates (1999, 1999b e 2001). 
ricano - o Long Term Capital Management -, em 1998, a crise cambial brasileira de 1999, e as crises da Argentina e Turquia (2000-2002), além de uma série de episódios de menor visibilidade fora dos meios especializados, mas igualmente relevantes, com destaque para a crise no pagamento dos Brady bonds do Equador, ${ }^{8}$ a instabilidade na Ucrânia, Paquistão e Venezuela, entre outros.

Conforme pode ser verificado nos gráficos 1 e 2, a entrada líquida de capital privado nos países em desenvolvimento atingiu seu auge no ano de 1996, com US\$ 233 bilhões. Com a crescente instabilidade internacional, aquele montante atingiu seu menor valor absoluto desde a crise da dívida dos anos 1980: US\$ 8,9 bilhões em 2000. Esta queda deve ser atribuída à forte retração nos créditos bancários e nos fluxos de investimentos em portfólio gráfico 3 - muito mais voláteis do que o investimento direto externo (IDE) (IMF, 2001b).

Em termos relativos, o ano de 1996 marcou o pico da entrada líquida de capitais nos emergentes: 3,5\% do PIB conjunto destes países (gráfico 4). A partir da crise asiática, este indicador caiu para níveis tão baixos quanto os verificados no período da crise da dívida dos anos 1980.

A mudança na natureza dos fluxos privados de capitais teria alterado a própria dinâmica das crises. O predomínio dos créditos bancários sindicalizados no boom dos anos 1970 e as crises do tipo "em conta corrente", tornaram o padrão de ajuste relativamente uniforme nas crises dos anos 1980. As crises cambiais eram eminentemente "nacionais", com um poder de transmissão limitado. Os pacotes oficiais de socorro ajustavam-se às necessidades correntes de pagamentos dos serviços da dívida externa e de sustentação de volumes normais de importação de bens e serviços. As reestruturações dos passivos envolviam um número relativamente reduzido de agentes. Vale dizer que, na crise da dívida dos anos 1980, a concentração das dívidas nas mãos de um grupo restrito de credores teria facilitado a coordenação dos seus interesses (KRUEGER, 2001).

${ }^{8}$ A crise do Equador tornou-se emblemática, por ser o primeiro país a não pagar as obrigações dos Brady bonds. Entre 1990 e 1997, 18 países aderiram ao plano do então Secretário do Tesouro dos EUA - Nicholas Brady - de securitizar suas dívidas improdutivas, com a transformação dos créditos bancários (empréstimos) em títulos negociáveis. 
Gráfico 1 - FLUXO LÍQUIDO DE CAPITAIS PARA OS PAÍSES EM DESENVOLVIMENTO, 1971-2001 ( US\$ BILHÕES)

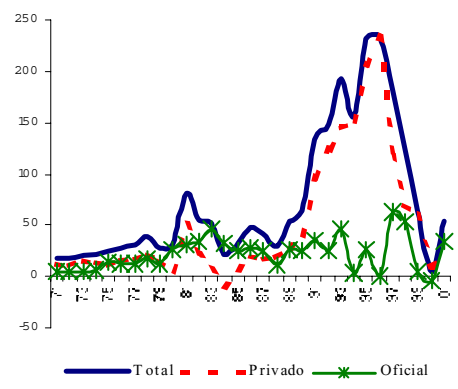

Gráfico 2 - FLUXO LÍQUIDO DE CAPITAIS (TOTAL E COMO PROPORÇÃO DO PIB) PARA OS PAÍSES EM DESENVOLVIMENTO, 1971-2001

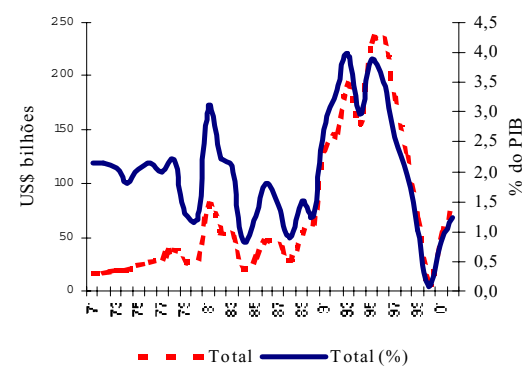

Gráfico 3 - COMPOSIÇÃO DOS FLUXOS PRIVADOS LÍQUIDOS DE CAPITAL PARA OS PAÍSES EM DESENVOLVIMENTO, 1980-2001 (US\$ BILHÕES)

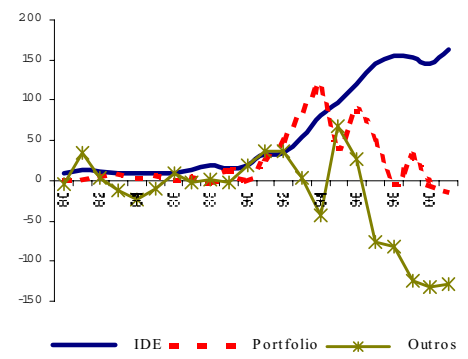


Gráfico 4 - FLUXO LÍQUIDO DE CAPITAIS PRIVADOS PARA OS PAÍSES EM DESENVOLVIMENTO COM RELAÇÃO AO PIB, 1971-2001 (\%)

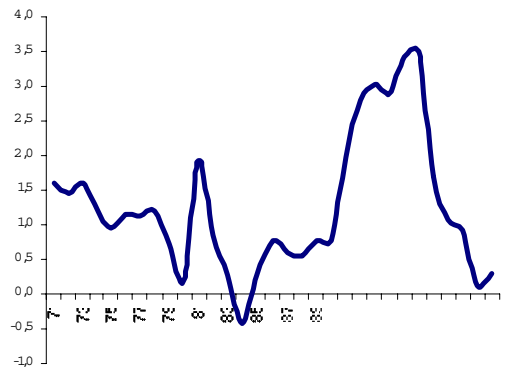

FONTE: Cálculos e elaboração do autor, a partir da base de dados do World Economic Outlook (IMF, 2001b)

Com a globalização financeira dos anos 1980 e 1990, passaram a predominar os fluxos de investimento direto e em portfólio. Houve uma ampliação tanto no volume de recursos - em termos absolutos e relativos (gráficos 1 a 4) - quanto no número de agentes envolvidos. A natureza das crises financeiras alterou-se, com o predomínio de crises da "conta capital", ou seja: reversões súbitas nos fluxos privados de capitais, motivadas por problemas domésticos ou pelo efeito-contágio - a faceta mais aparente dos comportamentos miméticos e irracionais dos mercados internacionais de capitais (CUNHA, 2001).

Ampliou-se a volatilidade dos fluxos de curto prazo (gráfico 3) e criou-se uma pressão crescente sobre as fontes oficiais de recursos. Os mega-pacotes de auxílio aos países em crise geraram um intenso debate sobre os perigos do risco moral, na medida em que os investidores internacionais tenderiam a agir de forma menos prudente em um ambiente onde as instituições multilaterais "garantiriam" a liquidez de seus ativos. Assim, por exemplo, no final de 1996, os recursos líquidos do FMI, usados para cobrir crises nos países membros, eram de US\$ 83 bilhões. Em dezembro de 1998, chegaram a US\$ 54 bilhões (COUNCIL OF ECONOMIC ADVISERS, 2002, p. 284-286). Em 1998, o Fundo solicitou US\$ 89 bilhões para seus membros, na forma de um Novo Arranjo de Empréstimo. Com isso, seus recursos atingiram US\$ 125 bilhões no final de 2001. Os pacotes oficiais liderados pelo Fundo - especialmente nas crises mexicana e asiática - envolveram recursos em volumes inéditos e forçaram a criação de novas linhas de financiamento, mais largas do que os convencionais Arranjos Stand-by. Ademais, a pulverização no 
número de credores e devedores tornou muito mais complexa a tarefa de reestruturação das dívidas improdutivas (COUNCIL OF ECONOMIC ADVISERS, 2002; CUNHA, 2001).

Assim, com a transição dos empréstimos sindicalizados (padrão anterior à crise dos anos 1980) para os títulos de dívida (padrão dos anos 1980 e 1990), enquanto instrumentos predominantes de canalização de recursos para os países em desenvolvimento, ter-se-ia estabelecido uma mudança radical na convergência de interesses. A pulverização do número de credores e a diversidade e complexidade dos instrumentos de dívida teriam estimulado a "corrida dos credores" sempre que, em sua percepção, a posição passiva de um país sinalizasse um grau inaceitável de liquidez. Credores poderiam estabelecer estratégias bem sucedidas de realização de ativos, mesmo em casos de flagrante "iliquidez" dos países devedores. Tais crises, com custos danosos em termos reais e financeiros, conforme destacado no item anterior, e que ademais, tenderiam a reduzir o acesso dos países atingidos aos fluxos privados de capitais por vários anos, deveriam ser evitadas. É neste contexto que se desenrola o debate sobre as limitações da infra-estrutura institucional que governa as relações privadas nos mercados financeiros internacionais. Passou-se a demandar mudanças na chamada arquitetura do sistema financeiro internacional (AFI), com ênfase para: (i) a fixação de parâmetros globais e instituições de regulação para os fluxos de capitais; (ii) a definição de regimes cambiais mais adequados à manutenção da estabilidade com abertura financeira; (iii) a definição de mecanismos de ordenamento dos conflitos entre credores e devedores; e (iv) a reestruturação no papel dos órgãos multilaterais, especialmente o FMI (EICHENGREEN, 1999, 1999b e 2001, ROGOFF, 1999, PARK; WANG, 2000, IMF, 2000, GOLDSTEIN, 2001, UNCTAD, 2001).

Os fóruns multilaterais - FMI, G7, BIS (Bank of International Settlements), OCDE (Organização para Cooperação e Desenvolvimento Econômico), FSF (Financial Stability Forum), entre outros - têm enfatizado a fixação de parâmetros regulatórios globais, a partir da experiência dos países centrais. ${ }^{9}$ Além disso, têm focalizado a necessidade dos governos nacio-

${ }^{9}$ O FSF (apud UNCTAD, 2001, p. 80) identificou os seguintes standards (em parênteses o órgão responsável): (i) Código de Boas Práticas na Transparência das Políticas Monetária e Financeira (FMI); (ii) Código de Boas Práticas na Transparência da Política Fiscal (FMI); (iii) SDSS e GDDS para transparência e disseminação de informações econômicas (FMI); (iv) Princípios e Guia em Sistemas Efetivos de Insolvência (BM); (v) Princípios de Governança Corporativa (OCDE); (vi) Padrões Internacionais de Contabilidade (Comitê da Associação Internacional de Contabilidade); (vii) Padrões Internacionais de Auditoria (Federação Internacional de Contadores); (viii) Princípios 
nais, nos países em desenvolvimento (devedores), adotarem tais padrões. $\mathrm{O}$ FMI e o Banco Mundial estão monitorando a implantação dos standards associados à solidez dos sistemas financeiros domésticos. Em maio de 1999, introduziram o Programa de Avaliação do Setor Financeiro, cujos Relatórios de Observância dos Códigos (ROCs), evidenciam o grau de adesão aos parâmetros recomendados. No final de setembro de 2001, 57 países estavam sendo monitorados - 36 ROCs já haviam sido publicados (COUNCIL OF ECONOMIC ADVISERS, 2002, p. 286).

Entende-se que este tipo de padronização institucional minimizaria a tendência de risco crescente associada às decisões de investimento em ativos pouco transparentes. Ou seja, os chamados mercados emergentes se caracterizariam por apresentarem graves falhas institucionais, tanto na supervisão dos seus sistemas financeiros, quanto na qualidade da governança empresarial. Com informações econômico-financeiras pouco transparentes, corrupção e insuficiências governamentais no que concerne à regulamentação dos mercados financeiros, o risco dos investidores internacionais ficaria super-dimensionado, ampliando, conseqüentemente, o potencial global de instabilidade. Assim, ao identificar nos países emergentes, a fonte da instabilidade, o establishment oficial (FISCHER, 1999 e 2001, SUMMERS, 1999, MELTZER, 2000, IMF 2000, G7, 2000) e privado (COUNCIL OF FOREIGN RELATIONS, 1999) emitiu um claro sinal de continuidade no processo de integração financeira internacional em um ambiente de liberalização-com-desregulamentação, ainda que com "reformas pontuais".

Não questionou-se a necessidade da constituição de instituições reguladoras globais - um tribunal internacional para a arbitragem de conflitos de dívidas, um banco central internacional, uma agência reguladora das finanças, uma companhia internacional de seguro de crédito, etc. ${ }^{10}$ - com

Fundamentais de Sistemas de Pagamentos Sistematicamente Importantes (Comitê Sobre Sistemas de Pagamento e Compensação do BIS); (ix) Integridade dos mercados e prevenção da lavagem de dinheiro por meio das "Quarenta Recomendações da Força de Tarefa de Ação Financeira (FTAF); (x) Princípios Fundamentais de uma Supervisão Bancária Efetiva (Comitê da Basiléia para Supervisão Bancária); (xi) Objetivos e Princípios da Regulação de Securities (IOSCO); (xii) Princípios da Supervisão de Seguros (IAIS).

${ }^{10}$ No âmbito das discussões do G7, o governo inglês propôs a criação de uma superagência global de regulação financeira, a partir da fusão do FMI, BM e BIS; a França, com o intuito de reduzir a influência dos EUA nas decisões do FMI, sugeriu ampliar o poder decisório do Comitê de Ministros das Finanças do Fundo; a Alemanha defendeu as target zones para as principais divisas internacionais, como forma de reduzir a instabilidade; e o Canadá alinhou-se à defesa de um maior poder de arbítrio do FMI sobre os credores, inclusive com a invocação de suspensão temporária do pagamento de dívidas em caso de crise (EINCHENGREen, 1999). Na linha globalista, Garten (1998) propôs a criação de um 
poder de coerção sobre os países centrais (credores). Esta perspectiva pouco convencional vem sendo defendida por vários especialistas da academia (AKYÜZ e CORNFORD, 1999, EATWELL e TAYLOR, 1998, SOROS, 1998, ROGOFF, 1999, UNCTAD, 2001). Três pontos sustentam a racionalidade destas propostas:

i) Argumenta-se que as instituições herdadas de Bretton Woods teriam nascido em um mundo onde a liberdade irrestrita aos fluxos de capitais era entendida como sendo incompatível com o objetivo maior: manutenção da estabilidade cambial com expansão do comércio sob bases multilaterais. Por conta disso, nem o FMI, nem o Banco Mundial ou a OMC (Organização Mundial do Comércio), possuiriam mecanismos legais capazes de dar conta da regulação da conta capital, nos marcos do estágio atual de avanço na integração financeira internacional;

ii) Sustenta-se que a internacionalização dos negócios teria modificado radicalmente as bases geográficas da regulação. Sem uma contrapartida adequada, em termos de regras e poder de coerção, também globais, haveria uma tendência permanente de instabilidade. Isto porque, segue o terceiro argumento;

iii) Os investidores privados tenderiam a explorar os diferenciais regulatórios, potencializando os comportamentos miméticos e irracionais dos boom and busts dos ciclos financeiros recentes.

Além disso, considera-se como central a percepção de que existe uma assimetria entre credores e devedores, com um viés para os primeiros, no que se refere à distribuição dos custos e benefícios do processo de globalização financeira. Diante das reformas em curso, entende-se que a ênfase na adoção de parâmetros regulatórios globais impõe um custo desproporcional sobre os governos nacionais dos países em desenvolvimento (UNCTAD, 2001). Nestes termos, Rodrik (2001) sustenta que os requisitos uniformizantes impostos pelos órgãos multilaterais aos países em desenvolvimento visam proteger os ativos dos investidores dos países centrais, mais do que garantir uma trajetória sustentável de desenvolvimento para a periferia. ${ }^{11}$

Banco Central Mundial; Sachs (1998 e 1998b) defendeu a criação de um tribunal internacional para o equacionamento de conflitos credor-devedor; e Soros (1998), uma agência de seguros global.

11 "Na arena financeira, as reformas complementares tem sido impostas com ainda mais fanfarra e urgência. A visão predominante em Washington e em outras capitais do G7 é que a fragilidade na regulação prudencial, na governança corporativa e nos procedimentos legais sobre falências, estavam no coração da crise financeira asiática. Daí o ambicioso esforço do G7 em estabelecer códigos e padrões internacionais cobrindo 
Para além da busca de maior transparência nas instituições públicas e privadas e da reestruturação no papel das instituições multilaterais, especialmente o FMI, a agenda de reformas da AFI tem gerado uma tendência de convergência temática entre algumas propostas acadêmicas "não convencionais" e sugestões vindas do próprio establishment oficial. Este ponto será enfatizado a seguir.

\section{FALÊNCIA SOBERANA}

A recorrência das crises financeiras, especialmente nos mercados emergentes, fez Krueger $(2001,2001 \mathrm{~b}$ e 2002) reconhecer que as medidas de fortalecimento da AFI adotadas no período pós crise asiática seriam insuficientes. Para a agora vice-diretora gerente do FMI, far-se-ia necessário discutir novos mecanismos de equacionamento das situações de iliquidez de países fortemente endividados. As operações de socorro dos órgãos multilaterais e de governos dos países credores - bail out - esbarrariam em dois obstáculos graves: a criação de risco moral nos credores privados e os limites orçamentários do $\mathrm{FMI}^{12}$ e de seus países-membros. A busca de envolver o setor privado, por meio da reestruturação voluntária das dívidas, por exemplo, - o bail in -, ajudaria a minimizar o problema do risco moral, porém não evitaria o surgimento de crises do tipo "profecia auto-realizada" por movimentos coletivos de realização dos ativos (as "corridas dos credores").

A solução vislumbrada pelo Fundo e externada pela primeira vez por Krueger (2001) aproxima-se do modelo de falência privada das

[temas como] a transparência fiscal, as políticas monetária e financeira, a supervisão bancária, a disseminação de dados, a governança corporativa, e os padrões contábeis. O Financial Stability Forum (FSF) - uma agência com nenhum país em desenvolvimento como membro - designou doze destes padrões como sendo a chave para [a constituição] de sistemas financeiros saudáveis nos países em desenvolvimento (...) Na perspectiva de como surgiram as demandas que originaram tais pré-requisitos, um cínico pode ser desculpado por imaginar que a razão de tudo estaria em se buscar garantir a cobertura de eventuais prejuízos [para as decisões de investimento dos agentes econômicos dos países centrais]. Afinal, quando de um desempenho decepcionante no crescimento ou uma crise financeira, é muito mais conveniente culpar os 'deslizes' na implementação das reformas complementares do que [culpar] um processo inadequado de liberalização.” (RODRIK, 2001, p. 3-4, grifos no original)

${ }^{12}$ Krueger destaca que, ao contrário dos Bancos Centrais que podem emitir moeda de curso forçado, o FMI não cria liquidez. Por isso, necessariamente, haveria limitações para o exercício de um emprestador em última instância, nos termos de Bagehot - fornecer, tempestivamente, uma significativa quantidade de recursos a taxas punitivas. 
corporações norte-americanas. Tratar-se-ia, portanto, da discussão de um arcabouço capaz de viabilizar processos de "falências soberanas", ou, nos termos do Fundo, de "reestruturação de dívida soberana", ou, ainda, "criar um catalisador que encoraje devedores e credores a unirem-se na reestruturação de dívidas insustentáveis de um modo tempestivo e eficiente". Seguindo a explicação de Krueger (2001) "este catalisador poderia tomar a forma de um arcabouço oferecendo ao país devedor proteção legal contra credores que estejam obstaculizando uma reestruturação necessária, em troca da obrigação para o devedor de negociar de boa fé com seus credores e implementar políticas que assegurem a prevenção do surgimento de problemas semelhantes no futuro."

Este tema não é propriamente novo. A UNCTAD (United Nations Conference on Trade and Development) vem defendendo a criação de mecanismos internacionais que permitam a reestruturação voluntária de dívidas soberanas pelo menos desde 1985 (UNCTAD, 2001). Além disso, a comunidade acadêmica tem elaborado várias propostas neste sentido. As premissas básicas são de que: (i) as crises financeiras geram um rastro de dívidas não honradas; (ii) não existem regras globais capazes de ordenar a reestruturação destes passivos, de forma voluntária ou coercitiva, bem como instituições com legitimidade para garantir a supervisão e o cumprimento dos acordos, o que dificulta o equacionamento das crises. As sugestões têm ido do incentivo ao bailing in dos investidores privados, preferencialmente de forma voluntária, até a criação de instituições capazes de fixar os termos de uma renegociação (EICHEENGREEN, 1999).

A unCTAD (2001), em linha com a sugestão de Sachs (1998, 1998b), defende a criação de uma Corte Internacional de Falências, por meio de um tratado internacional ratificado pelos membros da ONU, e que seria responsável pela aplicação de um Código de Falências capaz de evitar uma corrida contra os ativos dos devedores, especialmente no contexto de uma crise de liquidez, ao mesmo tempo em que se protegeriam os direitos dos credores. Sugere-se a adoção de mecanismos semelhantes ao capítulo 11 da lei norteamericana de falências, que estabelece os termos de reestruturação financeira no caso de uma liquidação. Esta lei permite a suspensão temporária do pagamento de dívidas, ao se considerar que, uma vez ilíquida, mas potencialmente solvente, qualquer corrida contra os ativos da liquidante torna-se prejudicial para a própria e para os credores enquanto grupo. Além disso, os credores podem ofertar o capital de giro que garantiria a continuidade das operações da liquidante, tendo prioridade no resgate desta nova dívida. Fixam-se, também, parâmetros para o alongamento e cancelamento de dívidas, conversões de dívida em capital, etc. (UNCTAD, 2001, p. 68). 
Uma alternativa menos radical seria a definição para os devedores de procedimentos para suspensão temporária dos pagamentos e de concessão de novos empréstimos capazes de lastrear o pagamento da dívida velha, na base de acordos voluntários. As dívidas soberanas seriam negociadas diretamente - credor versus devedor - e as dívidas privadas seriam equacionadas pelos judiciários nacionais. Os instrumentos de dívida poderiam definir, ex-ante, os termos de uma eventual renegociação como a de que o devedor comprometer-se-ia em aceitar os termos legais definidos pelo judiciário do país credor (EICHENGREEN, 1999, 1999b, 2001, e ROGOFF, 1999).

Esta alternativa é criticada pela UNCTAD, que defende uma distribuição mais eqüitativa do ônus derivado das situações de iliquidez. Isto só seria possível com a mediação de uma parte neutra, com legitimidade institucional e poder de coerção, evitando-se o abuso de poder na definição das cláusulas contratuais dos instrumentos de dívida (UNCTAD, 2001, p. 69). A adoção de Cláusulas de Ação Coletiva (CAC) nos instrumentos de dívida poderia ser a via do meio, ao permitir o equacionamento ordenado dos defaults em um cenário de envolvimento - bailing in - ex-ante dos credores, a partir de uma coerção legal: os governos dos países credores deveriam forçar legalmente a sua adoção (GROUP OF TEN, 1996, COUNCIL OF FOREIGN RELATIONS, 1999, GOLDSTEIN, 2001). Estas dificuldades e suas possíveis soluções foram consideradas por Krueger (2001, 2001b e 2002). A grande novidade, portanto, é que esta proposta pouco convencional está partindo do núcleo do establishment.

Krueger $(2001,2002)$ relata um caso que teria estimulado a proposta do Fundo de "falência soberana". A Elliott Associates teria sido bem sucedida na exigência legal do pagamento de commercial papers comprados em 1996 e que tinham a garantia do governo do Peru. A Elliot, um fundo de investimento especializado na aquisição de títulos de devedores problemáticos, aproveitou-se da lacuna temporal criada pelo processo de securitização de dívidas soberanas. Em outubro de 1995, o governo peruano havia anunciado um acordo para reestruturar a dívida de dois bancos peruanos que tinham garantias oficiais. Em novembro de 1996, fechou-se o acordo, com 180 credores. Estes aceitaram a conversão da dívida em Brady bonds e créditos à vista. Entre janeiro e março de 1996, quando os detalhes finais daquele acordo estavam sendo ultimados, a Elliot adquiriu créditos daqueles bancos com $50 \%$ de desconto sobre o valor de face de US\$20,7 milhões (COUNCIL OF ECONOMIC ADVISERS, 2002, p. 296-297).

Logo após a aquisição, a Elliot mandou uma notificação oficial de inadimplemento e, na seqüência, entrou com um processo na Suprema Corte de Nova Iorque, buscando o pagamento integral da dívida. Isto se deu antes do fechamento do acordo de conversão em Brady bonds. A Elliot sabia do 
acordo, mas optou por uma estratégia do tipo free rider, onde "o vencedor fica com tudo". E ela venceu. A Elliot convenceu as cortes, nos EUA e na Europa, a caucionar o pagamento dos Brady bonds do Peru dos credores que haviam feito o acordo de 1996, até que o governo honrasse um pagamento de US\$ 55,7 milhões - valor quase três vezes superior ao valor de face da dívida e cinco vezes maior do que o montante pago pela Elliot. Sem a possibilidade de se proteger do credor, por meio da declaração de "falência", e sob risco de ter de declarar default sobre a "nova dívida" - recentemente reestruturada, a exemplo do que ocorrera com o Equador -, o Peru teve de capitular: em outubro de 2000, pagou US\$ 56,3 milhões à Elliot.

A crise do Equador (1999-2000), antecipou esta tendência. Pela primeira vez, um dos 18 países que emitiram Brady Bonds deixou de honrar o pagamento dos juros destes títulos. O Equador atravessava um processo de forte retração econômica - no primeiro semestre de 1999, o PIB real experimentou uma contração anualizada de 15,4\% - iniciada em 1997 e 1998, com a queda no preço internacional do petróleo, problemas na produção primária devido às alterações climáticas - efeito El Niño - e queda na entrada autônoma de capitais em decorrência da instabilidade internacional - crise russa. Em agosto de 1999, o governo anunciou que iria atrasar o pagamento dos juros de uma tranche de títulos Brady bonds. Porém, continuou honrando os demais títulos.

Os credores reagiram negativamente a este "pagamento seletivo" e iniciaram um processo coletivo de realização de ativos, pressionando pela antecipação no pagamento dos juros e principal dos bonds. O país não suportou a pressão e deixou de honrar todos os Brady bonds e Eurobonds em vencimento. Até março de 2000, quando anunciou-se um pacote de US\$ 2 bilhões em créditos oficiais (FMI, Banco Mundial e BID), o governo manteve um intenso e conflituoso processo de negociação com um grupo de representantes de credores. Conseguiu-se, em maio, como pré-condição para o acesso aos recursos oficiais, um acordo que reestruturou o perfil da dívida (COUNCIL OF ECONOMIC ADVISERS, 2002, p. 287-288).

É neste contexto que Krueger (2001) admite que o Fundo "deveria estar preparado para dar seu apoio implícito à suspensão temporária do pagamento das dívidas de um país, desde que estivesse implementando um pacote significativo de ajustes econômicos e se dispusesse a negociar, de boa fé, com seus credores.". Em outras palavras, o Fundo estaria admitindo a necessidade de, "sob certas circunstâncias", apoiar processos de moratória. Uma heresia impensável há poucos anos atrás. Como isso se daria? Com o consentimento do Fundo ("versão forte" em KRUEGER, 2001, 2001b e 2002) ou com a interveniência dos credores ("versão fraca" em KRUEGER, 2002b), um país poderia solicitar a suspensão temporária do pagamento de suas 
dívidas, prazo em que abriria negociações para reestruturação dos débitos. Admitir-se-ia, então, a imposição temporária de controles sobre os fluxos de capitais. O FMI disponibilizaria o espaço, na forma de "regras do jogo", para que devedores e credores procedessem de forma voluntária e ordenada a reestruturação das dívidas.

Krueger (2001, 2001b e 2002) admite explicitamente a inspiração no modelo da legislação de falências dos EUA, onde as reestruturações das dívidas das corporações tendem a ocorrer mais na "sombra das leis" do que nos tribunais. Da mesma forma, há uma forte semelhança com os mecanismos do equacionamento de crises financeiras utilizadas no caso asiático e em outras crises, e que seguem o aporte das "Regras de Londres" (CUNHA, 2001). Krueger (2001) é muito enfática ao afirmar que, em última instância, os acordos deverão ser realizados pelas partes envolvidas, sem a imposição, pelo Fundo, de qualquer solução.

Para que tal mecanismo de reestruturação de dívidas soberanas seja viabilizado dever-se-ia garantir os seguintes princípios gerais: (i) que os credores não burlem a negociação por meio da busca de realizar seus instrumentos de dívida junto às cortes nacionais; (ii) que os credores tenham garantias de que o devedor irá agir de boa fé, o que passaria pela adoção de políticas econômicas adequadas a sua recuperação e pela não concessão de privilégios arbitrários a grupos de credores (internos versus externos, por exemplo); (iii) que o setor privado esteja disposto a prover novo crédito capaz de auxiliar na recuperação do devedor, gerando, por contrapartida, a possibilidade de assumir um status superior na hierarquia dos credores; e (iv) que um grupo minoritário de credores "não fure" o acordo da maioria, exigindo o pagamento nas condições contratuais originais (KRUEGER, 2001, 2001b, 2002).

A execução destes princípios introduziria uma série adicional de problemas, muitos dos quais já destacados anteriormente. Em primeiro lugar, há a questão do enforcement, ou seja, das bases legais de imposição destas normas gerais. Para evitar "arbitragens regulatórias", estas regras deveriam ser universalmente aceitas. A UNCTAD (2001) sugere a ratificação, na ONU, de um tratado internacional que sustente uma Lei de Falências e uma Corte Internacional. Esta proposta é muito mais radical do que as "regras de livre negociação" externadas por Krueger $(2001)^{13}$. Esta, defendeu, inicialmente,

${ }^{13} \mathrm{Na}$ segunda exposição do arcabouço preliminar do Fundo (KRUEGER, 2001 b), a diretora sugere a possibilidade de que os países-membros, por ampla maioria (3/ 5 dos membros com $85 \%$ dos votos), emendem os Atos Constitutivos do FMI, de modo a legitimá-lo no cumprimento desta nova função. Esta seria uma alternativa à proposta da UNCTAD (2001) de ratificar um tratado internacional que legitimasse uma legislação de falências e que criasse uma corte internacional. 
que o Fundo fosse o agente operador do arcabouço de reestruturação, na medida em que teria legitimidade para apontar a consistência dos ajustes implementado pelos credores. Ainda que, admitisse que o Fundo não estaria preparado para realizar arbitragem, nos termos de uma Corte de Falências, como fica subentendido na proposta da UNCTAD. As críticas do setor privado e do Tesouro dos EUA (TRUMAN, 2001, IIF, 2002, TAYLOR, 2002) levaram à sugestão de que uma agência independente poderia desempenhar este papel (KRUEGER, 2002b).

A questão da arbitragem sintetiza os principais problemas destacados por Krueger (2001, 2001b, 2002 e 2002b), na medida em que uma terceira parte deverá mediar o cumprimento, entre credores e devedores, das regras de negociação e de implementação dos termos acordados. Além disso, o papel de fornecedor de crédito por parte do Fundo deveria ser adequado à priorização do provimento da liquidez necessária ao fortalecimento das reservas cambiais, tendo em vista as despesas em transações correntes serviços essenciais e importações.

Esta proposta explicitada por Krueger surge em um momento de crescente questionamento sobre os benefícios da livre conversibilidade da conta capital. ${ }^{14}$ Com a retração na entrada autônoma de capitais privados nos países em desenvolvimento (gráficos 1 e 2), o aumento da instabilidade financeira, expresso em recorrentes crises, e o crescente questionamento acadêmico sobre os pretensos vínculos automáticos entre liberalização da conta capital e crescimento, o FMI passou a demonstrar uma maior cautela na exposição dos custos e benefícios da liberalização financeira. Um bom exemplo disso é o capítulo quatro do World Economic Outlook, de outubro de 2001 (IMF, 2001), denominado de "Integração Financeira Internacional e os Países em Desenvolvimento".

Confrontando duas medidas distintas ${ }^{15}$ de liberalização financeira com diversos indicadores de desenvolvimento econômico e financeiro, o

${ }^{14}$ Rodrik (1998) sugere que a abertura financeira não esteve associada a um maior crescimento, ao longo dos anos 1990. Posteriormente, o mesmo autor criticou os desequilíbrios entre os custos institucionais da promoção de reformas liberalizantes e os resultados efetivos em termos de desenvolvimento (RODRIK, 2001). Para um mapeamento mais amplo da literatura, ver IMF (2001).

${ }^{15}$ Uma primeira medida seria mais qualitativa, baseada na existência ou não de regras restritivas à livre mobilidade de capitais. Tal medida de restrição, baseia-se nas informações do Relatório Anual de Arranjos e Restrições Cambiais, do FMI. Por ser uma medida binária (com ou sem) ela não permite uma análise mais sensível sobre o grau de liberalização. A segunda medida, quantitativa, é dada pela soma dos estoques de ativos e passivos financeiros sobre o PIB, em uma analogia ao indicador de abertura comercial (exportações mais importações sobre o PIB). Assim, um países qualitativamente 
Fundo constata a existência de uma “... fraca relação entre crescimento e liberalização da conta capital e, como em outros estudos, tem dificuldade de encontrar relações significativas [entre crescimento e liberalização]."'(p.143). Ainda assim, seria possível identificar um efeito positivo sobre os investimentos e o desenvolvimento do setor financeiro. Por outro lado, os custos da liberalização, em termos de aumento da instabilidade, seriam evidentes, especialmente nos anos 1990. A ampliação da liberalização da conta capital, em muitos países em desenvolvimento, teria vindo acompanhada de aumento na volatilidade dos fluxos líquidos de capital e redução no crescimento econômico. ${ }^{16}$

Para o Fundo, a fraca ligação entre crescimento e liberalização financeira seria determinada por falhas institucionais dos países receptores. Quanto mais frágeis as instituições domésticas, especialmente de regulação dos mercados financeiros, maiores os custos potenciais da abertura frente aos benefícios potenciais. Desta forma, abre-se espaço para a consideração de que podem ser válidos controles temporários sobre as entradas de capitais com o intuito de alterar o perfil temporal dos investimentos ou garantir fôlego para a execução de um processo mais amplo de reestruturação dos passivos. A própria proposta de "falência soberana" está associada à idéia de uma limitação temporária - ainda que negociada - à livre conversibilidade da conta capital.

"fechado", por apresentar restrições à livre mobilidade de capitais pode ser "aberto" pelo indicador quantitativo, como no caso da China.

16 "Esses benefícios potenciais de longo prazo [ampliação dos investimentos, spill overs derivados do investimento direto externo, e o aprofundamento dos mercados financeiros], todavia, precisam ser confrontados com os perigos que os mercados financeiros internacionais abertos também podem criar, incluindo crises financeiras, com elevado custo em termos de produto. Os problemas estão geralmente associados com a entrada e saída excessiva de capitais e, de um modo mais geral, com a volatilidade dos fluxos líquidos de capital ... [essa volatilidade] tem crescido substancialmente ao longo do tempo, especialmente em países que experimentaram liberalizações da conta capital mais extensivas. $\mathrm{O}$ aumento da volatilidade tem sido mais pronunciado nos fluxos de portfólio do que nos fluxos de IDE, refletindo as relações de mais longo prazo implícitas ao IDE. A volatilidade tem sido particularmente alta nos anos 1990, quando da liberalização recente de muitos países em desenvolvimento. Nesta década, a maior volatilidade dos fluxos de capital tem, também, estado associada a um menor crescimento." (IMF, 2001, p. 161) 


\section{CONSIDERAÇÕES FINAIS}

A recorrência de episódios de crises financeiras, especialmente a partir da segunda metade dos anos 1990, estabeleceu um novo patamar de discussão sobre a arquitetura do SFI. A comunidade financeira internacional, os governos do G7, os órgãos multilaterais e a academia viram-se diante de um dilema: como preservar os parâmetros institucionais que garantiram a liberalização dos mercados e, assim, o boom das últimas duas décadas, e, ao mesmo tempo, reduzir o potencial instabilizador dos fluxos privados de capitais.

A "primeira geração" de reformas ganhou momento com a crise asiática. ${ }^{17}$ As instituições oficiais - FMI, BIS, World Bank, etc. - respaldadas pelos governos do G7, criaram uma agenda de fortalecimento dos "elos fracos"18 da cadeia dos mercados. Entendia-se que a crescente diversificação das carteiras de investimento de agentes relevantes dos países centrais - fundos de pensão, fundos mútuos, etc. - acabava por gerar a incorporação, também de forma crescente, de novos mercados ditos "emergentes". A maior fluidez dos fluxos de capitais seria alimentada pelas novas tecnologias de informação e gestão de investimentos, a liberalização e as inovações financeiras. Crises localizadas poderiam se espraiar em função de comportamentos coletivos - do tipo "manada" -, racionalizados em função dos elevados custos de transação associados ao escrutínio das características específicas de cada investimento.

Decisões de investimento alicerçadas em preços distorcidos ampliariam o risco das crises. Estas, via efeito-contágio, poderiam contaminar economias mais sólidas, simplesmente por pertencerem a uma mesma categoria de investimento - "mercados emergentes". As distorções de preços seriam originadas não somente pelas más políticas fiscal e monetária - como nos velhos modelos de crises cambiais -, mas, também: (i) por falhas institucionais - garantias governamentais implícitas, governança corporativa

${ }^{17}$ A crise mexicana de 1994, e mesmo a crise do SME, em 1992-1993, já havia causado um mal-estar na comunidade financeira, academia, governos do G7 e instituições multilaterais. Seu impacto maior, contudo, foi no plano das discussões teóricas sobre as crises financeiras. Somente com a crise asiática esse mal-estar transformou-se em "urgência normativa", gerando ações concretas (CUNHA, 2001).

18 Analogia do presidente do FED, Alan Greenspan (1997) ao comentar a crise asiática. Para ele o sistema financeiro internacional seria como uma corrente, cuja consistência dependeria da força dos elos mais fracos. Ou seja, se a há fragilidades macroeconômicas e institucionais nos emergentes (os elos fracos) a corrente como um todo fica prejudicada. 
inadequada, corrupção, etc.; e (ii) informacionais - opacidade das informações econômicas, nos níveis micro e macroeconômico.

Por conta dos anteriores, a "primeira geração" de reformas da AFI irá priorizar a disseminação de best practices de regulamentação dos sistemas financeiros, da gestão fiscal, da governança corporativa, das normas contábeis, etc. Caberia aos países em desenvolvimento, especialmente aqueles integrados nas carteiras dos investidores dos países credores - os "mercados emergentes" - adotarem tais parâmetros, alinhando suas instituições domésticas aos padrões aceitos nos países centrais. Em tese, este alinhamento tenderia a minimizar os erros de avaliação dos investidores e, assim, o risco de crise.

Há uma hipótese "implícita” neste enfoque: as crises são causadas fundamentalmente pelas falhas políticas e institucionais dos países receptores dos investimentos. Este ponto está longe de representar um consenso teórico ou político (CUNHA, 2001, CUNHA; PRATES, 1999, 1999b e 2001). Há evidências de que as crises podem se originar de falhas de mercado pelo lado da oferta, ou seja, nos comportamentos miméticos e irracionais dos investidores internacionais. Além disso, parte da comunidade privada, acadêmica e, mesmo oficial, admite a existência de uma assimetria de tratamento dos interesses de credores e devedores, com um viés favorável aos primeiros, o que refletiria a incompatibilidade entre as dimensões atuais do mercado global de capitais e suas instituições reguladoras - ou a ausência de tais instituições (sTIGLITZ, 2000, RODRIK, 2001, soros, 1998, RADALET; SACHS, 1998, 1998b, UNCTAD, 2001).

A proposta lançada por Anne Krueger de se discutir a conformação de um arcabouço institucional capaz de ordenar os processos de reestruturação das dívidas de países "potencialmente" em crise, sugere que as reformas de "primeira geração" da AFI já estão sendo consideradas insuficientes no núcleo duro do establishment oficial. Este é um reflexo do agravamento das condições de financiamento externo dos mercados emergentes, da fragilidade de alguns países-chaves e do comportamento oportunista de investidores internacionais. Ainda que embrionária e com desdobramentos políticos e práticos ainda incertos, deve-se considerar como positiva a postura pragmática do FMI.

Nunca é demais lembrar que os atos constitutivos do Fundo previam a possibilidade de controles temporários sobre os fluxos privados de capitais, sempre que isso estivesse associado a uma situação de grave fragilidade do balanço de pagamentos. O “espírito” de Bretton Woods ressaltava a necessidade de se garantir a ampliação dos fluxos de comércio - a conversibilidade da conta corrente - sob bases multilaterais, mesmo que isso impli- 
casse a assunção da existência de limites temporários à conversibilidade da conta capital. Era o pragmatismo do pós-guerra. A globalização financeira retirou da agenda política o tema dos limites à livre mobilidade de capitais ainda que temporários. Porém, a instabilidade dos últimos anos está resgatando a necessidade da criação de mecanismos capazes de conter os efeitos disruptivos das crises financeiras.

A hipótese da "falência soberana" não é propriamente nova. Seu detalhamento levantará uma série de problemas, especialmente no que se refere ao seu enforcement legal e legitimidade da arbitragem. Ainda assim, o simples fato deste tema estar sendo objeto de discussão a partir de uma iniciativa do próprio Fundo, sinaliza um avanço não desprezível, pelo menos em dois sentidos. Em primeiro lugar, criou-se um novo patamar no debate, no qual os interesses oficiais e privados passam a ser explicitados. A visão simplista de que a instabilidade financeira atual é resultado, somente, das fragilidades dos países em desenvolvimento tende a perder força. Em segundo lugar, o descompasso entre a internacionalização dos mercados e o poder regulatório dos estados nacionais impõe a necessidade de serem criadas novas instituições e/ou fortalecidas instituições já existentes, e que tenha um caráter multilateral.

Porém, para além de sua criação/fortalecimento há que se garantir um maior equilíbrio na atuação de tais instituições. Observadores atentos e bem informados como Stiglitz (2000), Rodrik (2001), Sachs (1998, 1998b), Soros (1998), entre outros, sugerem que órgãos como o FMI tendem a tomar decisões visesadas por interesses dos países credores ou, mais especificamente, de grupos específicos dentro daqueles. Reproduz-se, no plano institucional, as assimetrias de poder econômico e político que separam os países centrais dos periféricos. Portanto, ainda que a atual proposta de "falência soberana" tenha nascido sob o signo conservador do Fundo, e possa gerar como resultado final um arcabouço que vise mais à proteção dos credores do que dos devedores, não se pode deixar de reconhecer que uma nova frente de debate foi aberta. Esta heresia desde dentro também poderá gerar avanços institucionais que reduzam as assimetrias no tratamento de interesses entre duas partes contratantes de uma dívida soberana. Se na década passada esta era uma alternativa fechada, agora, de forma até irônica, cria-se, a partir do FMI, um espaço potencial de aprimoramento da base institucional que regula as relações de mercado no plano das finanças internacionais. 


\title{
RESUMO
}

A recorrência das crises financeiras, especialmente a partir da crise asiática de 1997-1998, determinou a emergência de um amplo debate e de um conjunto de ações políticas visando à reforma da arquitetura do sistema financeiro internacional. O presente artigo enfoca, dentro deste marco mais geral, a questão da "falência soberana". A proposta lançada por Anne Krueger de se discutir a conformação de um arcabouço institucional capaz de ordenar os processos de reestruturação das dívidas de países "potencialmente" em crise sugere que as reformas de "primeira geração" já estão sendo consideradas insuficientes no núcleo duro do establishment oficial.

Palavras-chave: falência soberana, crises financeiras, arquitetura do sistema financeiro internacional, liberalização financeira.

\begin{abstract}
The recurrence of financial crises, particularly after the Asian meltdown (1997-1998), determined the emergence of an intense debate and new policies concerning the international financial architecture. In this context, this paper discuss the recent Anne Krueger's approach to sovereign debt restructuring. We suggest that this new approach reveals that the "first generation" reforms seem to be already insufficient, even for the hardcore of the official establishment.

Key-words: Sovereign debt, financial crises, international financial architecture, financial liberalization.
\end{abstract}

\section{REFERÊNCIAS}

AKYÜZ, Yilmaz; CORNFORD, Andrew. Capital Flows to Developing Countries and the Reform of the International Financial System. Unctad Discussion Paper, n. 143. Genebra: United Nations Conference on Trade and Development - United Nations, 1999.

AZIZ, Jahangir; CARAMAZZA, Francesco; SALGADO, Ranil. Currency Crises: in search of common elements. IMF Working Paper, WP/00/67. Washington, DC: International Monetary Fund, 2000.

COUNCIL OF ECONOMIC ADVISERS. Economic Report of the President, 2002. Washigton, DC: United States Government Print Office, 2002. 
COUNCIL OF FOREIGN RELATIONS TASK FORCE. Safeguarding Prosperity in a Global Financial System: the future international financial architecture. Washington, DC: Institute for International Economics, 1999.

CUNHA, André Moreira. Crise no Pacifico Asiático: causas e conseqüências. Campinas, 2001. Tese (Doutorado) - Instituto de Economia, Unicamp. (não publicada).

; PRATES, Daniela Magalhães. A instabilidade financeira nos anos 90: implicações para as economias capitalistas periféricas. In: ENCONTRO NACIONAL DE ECONOMIA POLÍTICA, 4., 1-4 jun. 1999, Porto Alegre. Anais... Porto Alegre: UFRGS, 1999.

; PRATES, Daniela. Instabilidade financeira nos anos 90: a reação conservadora. In: JORNADA DE ECONOMIA POLÍTICA DO CAPITALISMO CONTEMPORÂNEO, 2.; ENCONTRO NACIONAL DE ECONOMIA, 27., 7-10 dez. 1999, Belém. Anais...Belém: Anpec, 1999b.

; PRATES, Daniela. Instabilidade e crises: os avanços teóricos e as limitações políticas para o desenvolvimento dos países periféricos. In: SEMINÁRIO INTERNACIONAL DESENVOLVIMENTO NO NOVO SÉCULO - Centenário do Nascimento de Raúl Prebisch, 30 ago.-1 set. 2001, Rio de Janeiro.

DEMIRGÜÇ-KUNT, Asli; DETRAGIACHE, Enrica. Financial Liberalization and Financial Fragility. IMF Working Paper, 98/83, jun. 1998. Washington, DC: International Monetary Fund.

EATWELL, John; TAYLOR, Lance. International Capital Markets and the Future of Economic Policy. CEPA Working Paper Series III, n. 9, 1998.

EICHENGREEN, Barry. Toward a New International Financial Architecture: a practical post-Asia agenda. Institute for International Economics, 1999.

(1999b). Strengthening the International Financial Architecture: where do we stand? Disponível em: <http://emlab.berkeley.edu/users/eichengr/policy.htm>

(2001). Strengthening the International Financial Architecture: open issues, Asian concerns. Disponível em: <http://emlab.berkeley.edu/users/eichengr/policy.htm>

FISCHER, Stanley. On the Need of International Lender of Last Resort. Washington: International Monetary Fund, 1999.

Asia and the IMF. Washington: International Monetary Fund, 2001.

GARTEN, Jeffrey. In This Economic Chaos, a Global Central Bank Can Help. International Herald Tribune, sep. $25^{\text {th }}, 1998$. p. 8.

GOLDSTEIN, Morris. An Evaluation on Proposals to Reform on International Financial Architecture. NBER Conference on Management of Currency Crises, 2001.

GREENSPAN, A. Remarks by Chairman Alan Greenspan at the Economic Club of New York, NY (dec. 2), 1997. (mimeo)

GROUP OF TEN (1996). The Resolution of Sovereign Liquidity Crises. Report to the Ministers and Governors Prepared Under Auspices of Deputies. Disponível em: < www.bis.org/publ/other.htm\#Gten >

IIF. Sovereign Debt Restructuring. Washington, DC: Institute of International Finance, 2002. Disponível em: <www.iif.com>

IMF. World Economic Outlook. Washington: International Monetary Fund, may 1998. 
International Financial Architecture: an updade on bank activities. Development Committee, DC/2000-20. Washington DC: International Monetary Fund, 2000.

World Economic Outlook. Washington: International Monetary Fund, oct. 2001.

World Economic Outlook. Washington: International Monetary Fund, dec. 2001b.

KAMINSKY, G.; REINHART, C. The Twin Crises: the causes of banking and balance of payments problems. IMF Discussion Papers, n. 544, mar. 1995. Washington DC: International Monetary Fund.

; LIZONDO, S.; REINHART, C. Leading Indicators of Currency Crisis. Washington DC: IMF, 1998. (mimeo)

KRUEGER, Anne. International Financial Architecture for 2002: a new approach to sovereign debt restructuring. Speech at the National Economists' Club Annual Members' Dinner American Enterprise Institute, Washington DC, nov. 26, 2001. Disponível em: $<$ http://www.imf.org/external/np/speeches/2001/112601.htm>

. A New Approach to Sovereign Debt Restructuring. Speech at the Indian Council for Research on International Economic Relations. Delhi, India, dec. 20, $2001 \mathrm{~b}$. Disponível em: < http://www.imf.org/external/np/speeches/2001/122001.htm >

. The Evolution of Emerging Market Capital Flows: why we need to look again at sovereign debt restructuring. Speech at the Economics Society Dinner, Melbourne, Australia, jan. 21, 2002. Disponível em: <http://www.imf.org/external/np/speeches/2002/ 012102.htm>

. A New Approach to Sovereign Debt Restructuring. Washington: International Monetary Fund, 2002b.

MISHKIN, Frederic S. Financial Policies and the Prevention of Financial Crises in Emerging Market Countries. NBER Working Paper, 8087. Cambridge, Massachusetts: National Bureau of Economic Research, 2001.

PARK, Chul Yung; WANG, Yunjong. Reform of the International Financial System and Institutions, 2000. (mimeo)

RADALET, Steven; SACHS, Jeffrey D. The Onset of the East Asian Financial Crisis. NBER Working Paper 6680. Cambridge, MA: National Bureau of Economic Research, 1998.

The East Asian Financial Crisis: Diagnosis, Remedies, Prospects. Brookings Papers on Economic Activity, n. 1. Washington, DC: Brookings Institution, 1998b.

RODRIK, Dani (1998). Who Needs Capital-Account Conversibility? Disponível em: $<\mathrm{http}: / / \mathrm{ksghome}$.harvard.edu/ .drodrik.academic.ksg/papers.html>

(2001). The Developing Countries Hazardous Obssession with Global Integration. Disponível em: <http://ksghome.harvard.edu/ .drodrik.academic.ksg/papers.html>

ROGOFF, Kenneth. International Institutions for Reducing Global Financial Instability. NBER Working Paper, 7265. Cambridge, Massachusetts: National Bureau of Economic Research, 1999.

SACHS, J. D. Global Capitalism: making it work. The Economist, sept. $12^{\text {th }} 1998$. Creditor Panics: causes and remedies. 1998b. (mimeo). 
CUNHA, A. M. Falência soberana: uma heresia...

SOROS, George. The Crises of Global Capitalism. New York: Public Affairs Press, 1998.

STIGLITZ, J. E. A globalização e os seus malefícios. São Paulo: Futura, 2000.

TAYLOR, John (2002). Sovereign Debt Restructuring: a U.S. perspective. Disponível em: <http://www.treas.gov/press/releases/po1016.htm>

TRUMAN, Edwin M. (2001). Perspectives on External Financial Crises. Washington, DC: Institute for International Economics. Disponível em: <http://www.iie.com/papers/ truman1201.htm>

UNCTAD. Trade and Development Report, 2001. Genebra: United Nations Conference on Trade and Development - United Nations, 2001. 